\title{
Linguagem, filosofia e exegese em duas obras de Santo Agostinho
}

\begin{abstract}
Antonio Carlos Olivieri ${ }^{1}$
Resumo: Tomando como ponto de partida o ensaio "Sermo humilis", de Erich Auerbach, sobre a inovação promovida por Santo Agostinho na tradição da retórica clássica e exposta de modo teórico em De Doctrina Christiana, este artigo pretende mostrar como os conceitos sobre linguagem apresentados nessa obra agostiniana foram desenvolvidas cerca de 20 anos antes pelo Autor, em seu diálogo De Magistro, que investiga a linguagem e propõe uma semiótica avant la lettre. Nossa interpretação do De Magistro, porém, procura evidenciar como a pesquisa linguística em Agostinho tem caráter epistemológico e, principalmente, exegético, na medida em que o diálogo nos parece basicamente um comentário ao versículo 23, 10 de São Mateus: "um só é o vosso Mestre, Cristo".

Palavras chave: Santo Agostinho, retórica, linguagem, filosofia, filologia, exegese.

Abstract: Having as our starting point the essay "Sermo humilis", by Erich Auerbach, on the innovation promoted by Saint Augustine on the tradition of classical rethoric and exposed theoretically in $D e$ Doctrina Christiana, this article intends to show how the concepts on language presented in this Augustinian work were developed about 20 years before by the Author, in his dialogue De Magistro, which inquires into language and proposes a semiotics avant la lettre. Our interpretation on De Magistro, however, has the purpose of pointing out how the linguistical research in Augustine has, mainly, epistemological and exegetic features, as the dialogue seems to us basically a comment on the 23,10 Matthew's verse: "for you have one Teacher, the Christ".

Keywords: Saint Augustine, rethoric, language, philosophy, philology, exegesis.
\end{abstract}

Sed inumerabilis multitudo signorum, quibus suas cogitationes homines exurunt, in verbis constituta est

De Doctrina Christiana, II, 4.4

Em ensaio intitulado "Sermo humilis", o filólogo Erich Auerbach (2012) investiga a influência exercida pelo cristianismo na Retórica, tal qual a disciplina foi concebida desde a Grécia Clássica e posteriormente aprimorada pelo gênio romano. Seu ponto de partida é o sermão de número 256 na edição maurista das obras de Santo Agostinho, que Auerbach constata ser marcado pelas características da Retórica da Antiguidade. No entanto, observa o estudioso alemão, se "as figuras do nosso texto derivam da tradição retórica acadêmica", por outro lado "o efeito final é de simplicidade, subordinadas que estão à clareza pedagógica, e a construção das frases soa por vezes quase coloquial" (p. 35).

Diante do contraste de um discurso caracterizado simultaneamente pela sofisticação do estilo e pela simplicidade, o filólogo se pergunta que modificações teriam sofrido as formas tradicionais da retórica, sob o peso dos novos conteúdos cristãos, e em que medida elas podem ter sido acomodadas no sistema da retórica antiga. A pergunta é particularmente significativa no contexto histórico em que se insere a obra de Agostinho de Hipona, o Baixo Império, quando o mundo antigo e a civilização greco-romana se encontram num momento de transformação profunda, identificado convencionalmente como o limiar entre a Antiguidade e a chamada Idade Média.

Para responder a essas questões, Auerbach nos remete ao livro IV, caps. 12 e ss. de A doutrina cristã (Agostinho, 2007), obra, acrescentemos, de caráter enciclopédico em que o bispo de Hipona lança as bases da "cultura cristã" (cf. Marrou, 1938). O

${ }^{1}$ Graduado em Letras Vernáculas pela FFLCHUSP, é jornalista e tradutor. Cursa o mestrado em Italiano também na USP. 
quarto e último livro desse tratado, cuja redação se iniciou em 397 d.C., mas só foi concluída circa 427 d.C., dedica-se à maneira de ensinar a doutrina de Cristo e concentra-se no estudo dos princípios fundamentais da retórica, que Santo Agostinho reputa útil, embora não indispensável, ao pregador cristão, conforme se pode ver no parágrafo 3 do capítulo 2 :

É um fato que, pela arte da retórica, é possível persuadir o que é verdadeiro como o que é falso. Quem ousará, pois, afirmar que a verdade deve enfrentar a mentira com defensores desarmados? Seria assim? Então, esses oradores, que se esforçam para persuadir o erro, saberiam desde o proêmio conquistar o auditório e torná-lo benévolo e dócil, ao passo que os defensores da verdade não o conseguiriam? Aqueles apresentariam seus erros com concisão, clareza, verossimilhança e estes apresentariam a verdade de maneira a torná-la insípida, de difícil compreensão e finalmente desagradável de ser crida? Aqueles, por argumentos falaciosos, atacariam a verdade e sustentariam o erro, e estes seriam incapazes de defender a verdade e refutar a mentira? (Agostinho, 2007)

Trata-se de um parágrafo que podemos considerar duplamente retórico, uma vez que emprega uma linguagem ornamentada com o intuito de persuadir, ou seja, se utiliza dos recursos da arte oratória - antíteses, hipérboles, expressão diatríbica, etc. para advogar a importância de utilizá-los no apostolado cristão. Além disso, o trecho serve para evidenciar o quanto a retórica está sempre presente na linguagem agostiniana, marcada pela eloquência, que o próprio autor define como "os princípios e preceitos dessa arte [a Retórica] unidos ao emprego engenhoso da linguagem, especialmente exercitada a realçar a riqueza do vocabulário e do estilo" (Agostinho, 2007).

Para confirmar a importância que o bispo de Hipona atribui à arte do orador, não se pode deixar de mencionar a recepção entusiástica que o público da Antiguidade dá à oratória, desde o florescimento dos Sofistas gregos até o Baixo Império, como se pode ver pelo que escreve em epístola o próprio Agostinho, a propósito da multidão que acorreu a assistir a um debate entre ele e um bispo donatista numa igreja em Turbussicum: "Eu via bem poucos naquela multidão que haviam vindo ali pela utilidade e a saúde de sua alma; todos os outros estavam ali para se deleitar com o espetáculo de nossa disputa, como se estivessem no teatro" (apud Marrou, p. 513).

Mas voltemos a Auerbach. Segundo o filólogo alemão, Agostinho, ao expor sua concepção de retórica, tem em mente a tripartição clássica dos níveis de estilo sublime, médio e baixo -, herdada de Cícero. No entanto, enquanto o grande orador latino prescreve ou recomenda uma adequação do estilo ao tema, o doutor da Igreja não reconhece a separação de temas em níveis, pois a Revelação - tema exclusivo do pregador eclesiástico, a quem se dirige preferencialmente o livro IV do De Doctrina (cf. Marrou, 1938, p. 507) - é sempre sublime. Portanto, para o bispo de Hipona, é a situação e a intenção do orador que deve determinar o nível do estilo a ser utilizado.

Ou, nas palavras de Auerbach:

Para o ensino e a exgese, [Agostinho] recomenda o estilo baixo, o qual, segundo Cícero, se não deve ser adornado, nem por isso pode ser displicente ou incorreto; o médio (temperatum), onde as figuras retóricas têm seu lugar natural, caberia ao elogio e à repreensão, à admoestação e à dissuasão; e o estilo grandioso ou sublime, que não exclui mas também não depende das figuras retóricas, deveria suscitar 
os grandes transportes de emoção, destinados a introduzir os homens à ação. (Auerbach, 2012, p. 36)

A recomendação de Agostinho constitui um aspecto inovador quanto ao uso dos princípios da retórica, que conduzirá Auerbach a detectar, a partir dele, o surgimento de um novo estilo de representação literária, ao qual chama de sermo humilis, "que ensina as profundezas da fé aos simples, que nos representa o Deus vivo e agonizante, ele próprio vil e desprezado, entre homens de baixa condição, e que, a fim de despertar os grandes movimentos da alma, não desdenha escolher suas imagens entre objetos de uso comum. O sermo humilis, que permanece humilde mesmo quando é figurado, sempre esteve ligado intimamente às origens e à doutrina do cristianismo, mas foi apenas o grande espírito de Santo Agostinho, onde por vezes se chocavam o mundo antigo e a fé cristã, que tomou consciência do fato. Talvez não seja exagerado dizer que foi ele que deu à Europa o sermo humilis, dessa maneira fundando, nesse domínio como em outros, a cultura medieval, lançando as bases desse realismo trágico, dessa mistura de estilos que, a bem dizer, só viria a se desenvolver muitos séculos mais tarde". (Auerbach, idem, p. 27)

Não se trata, contudo, e apesar de seu alcance e importância, da única inovação que se encontra na obra do autor de Confissões, no que se refere à Retórica e à eloquência, entendidas no sentido amplo que os termos tomaram no Império romano: "não a eloquência no sentido estrito, mas de modo mais geral a expressão literária", como se vê no último capítulo de Saint Augustin e la Fin de la Culture Antique (1938, p. 506). Nessa obra fundamental, Marrou apresenta pelo menos outro elemento de ruptura com a cultura clássica que deve ser mencionado. Ao notar que em Cícero já se encontra uma crítica à eloquência vazia, sem outro fim que sua própria perfeição, o historiador francês mostra que Santo Agostinho "retoma e aprofunda essa crítica" para reprovar como "ímpia a arte literária enquanto atividade especificamente estética" (p. 510).

Para o bispo de Hipona, o emprego dos recursos retóricos ou literários da expressão verbal subordina-se ao conteúdo a ser apresentado pelo orador, isto é, as verdades da Revelação. Em suas próprias palavras, no De doctrina christiana (IV, 29, 61), "nec doctor verbis serviat, sed verba doctori", lema que, com a pungência das sententiae latinas, evidencia não só a crítica à "ideia geral de uma literatura fundada sobre a busca do prazer estético, mas ainda o aspecto particular que ela tomara sob a influência da Segunda Sofística: o culto excessivo da forma e, nela, a busca de detalhes, o abuso dos 'ornamentos', o matraquear verbal, o gosto pelo gênero epidíctico, os panegíricos e outros discursos de circunstância” (Marrou, 1938, p. 511).

Segundo o historiador francês, entretanto, da crítica à retórica vazia e à "idolatria" dos praecepta dos retores, Agostinho avança para uma conclusão mais radical, que o leva a considerar desnecessário o aprendizado de retórica para o orador cristão. Quanto a isso, a posição do autor de A doutrina cristã fica bem clara, dentre outras passagens, em seu capítulo 16, § 32: “Assim, o nosso orador age eficazmente quando fala da justiça, da santidade e da virtude, aliás ele não deve falar sobre outra coisa. Faz tudo o que lhe é possível ao tratar desses assuntos, de maneira a ser entendido, apreciado e obedecido. E não duvide que se pode fazê-lo e o quanto pode, consegui-lo-á, mais pela piedade de suas orações do que por seu talento de orador. Assim, orando por si e por aqueles a quem falará, deve ser orante, antes de ser orador (conclusão, diga-se de pasagem, que também tem sabor de máxima: sit orator antequam dictor)".

Afirmar o caráter desnecessário da retórica e da eloquência tem um significado histórico cuja amplitude tem de ser bem compreendida, segundo Marrou (id., p. 517), pois significa "nada menos que romper com uma tradição oito vezes secular, opor-se àquilo que, para os homens de seu tempo, parecia o essencial da 
cultura. Separar a eloquência da retórica, conceber toda uma formação do orador que deliberadamente ignorará essas receitas, essa arte sobre a qual há séculos tanta atenção foi concentrada, isso é verdadeiramente inovar".

De qualquer modo, se Agostinho subordina a forma do discurso ao seu conteúdo, isso ocorre no interior de uma outra subordinação no pensamento agostiniano, de uma outra hierarquia, na qual se antepõe o ler ao falar ou redigir, a compreensão à exposição, o aprender ao ensinar. Sobre isso, concentraremos agora nossa atenção:

"insistirei sobre o fato de que esse problema de trabalhar [isto é, de expor a doutrina] aparece em Santo Agostinho como um problema secundário, subordinado. $\mathrm{O}$ problema fundamental é para ele o estudo da Escritura. Ler a Bíblia, estudá-la e compreendê-la é a tarefa essencial que se impõe a todo cristão suficientemente dotado para o trabalho intelectual. Ao contrário, ensinar, espalhar ao redor de si as verdades assim adquiridas, não aparece como uma exigência também direta e universal. [...] na escala de valores a descoberta da verdade deve ser posta bem acima de sua transmissão" (Marrou, 1938, p. 507).

Por isso mesmo os três primeiros livros de $A$ doutrina cristã se dedicam à leitura das Escrituras e à sua interpretação, sendo a obra considerada um "verdadeiro tratado de exegese" (Portalier, 1931). Já nas primeiras linhas do Prólogo, por exemplo, Agostinho afirma: "A respeito da interpretação das Escrituras existem certas normas que me parecem poder ser ensinadas com proveito aos que se dedicam a esse estudo. (...) Proponho-me a comunicar essas normas aos que desejam e são capazes de aprendê-las..." (p. 31). Em seguida, estabelece: "Há duas coisas igualmente importantes ao investigar as Escrituras: a maneira de descobrir o que é para ser entendido e a maneira de expor com propriedade o que foi entendido (I, 1.1, p. 41)", com o que deixa clara a dicotomia e a hierarquia entre seus membros apontada por Marrou.

Agostinho prossegue, postulando, já em I.2.2, uma nova dicotomia, que obriga o tratado à divisão em duas partes, uma sobre as coisas (de rebus), que corresponde ao livro I, e outra sobre os sinais (de signis), a que correspondem os livros II e III: "Toda doutrina reduz-se ao ensino das coisas e a dos sinais" (Outra máxima: Omnis doctrina vel rerum est vel signorum)". Vale a pena acompanhar mais de perto a exposição de Agostinho sobre os sinais, nos capítulos iniciais do livro II, em que se evidencia, antes de mais nada, a percuciência do pensamento agostiniano, que antecipa, em mais de um milênio e meio, algumas reflexões da Linguística e da Semiótica contemporâneas. Para começar, nosso autor define o termo sinal, como sendo "toda coisa que, além da impressão que produz em nossos sentidos, faz com que nos venha ao pensamento outra ideia distinta" (Signum est enim res, praeter speciem quam ingerit sensibus, aliud aliquid ex se faciens in cogitationem venire). Ou seja, o sinal se divide em algo que produz uma impressão sensível, que se poderia identificar ao significante saussureano, e a ideia que, distinta daquilo que produz a impressão, o sinal traz à nossa mente, em termos saussureanos, o significado.

A seguir, em II, 2.3, Agostinho divide os sinais em "naturais" (naturalia) e "convencionais" ou "intencionais" (data), explicando o primeiro tipo por meio de exemplos, dos quais basta citar apenas um para evidenciar aqui de que se trata: a pegada de um animal (vestigium transeuntis animantis). Sobre os sinais convencionais, nosso autor recorre a uma definição, antes de chegar a um exemplo, dada a complexidade crescente da semiologia que desenvolve: "Sinais convencionais 
(data signa) são os que todos os seres vivos mutuamente se trocam para manifestar - o quanto isto lhes seja possível - os movimentos de sua alma, tais sejam as sensações e o pensamento. Não há outra razão para significar, isto é, para dar um sinal, a não ser expor e comunicar ao espírito dos outros o que se tinha em si próprio, ao dar o sinal".

Ressalvando que esse tipo de sinal também se manifesta entre os animais irracionais $^{2}$, Agostinho declara que são os sinais convencionais que pretende examinar, "no que se refere aos homens", "porque os sinais que nos foram comunicados por Deus, e que se encontram nas Santas Escrituras, foram-nos comunicadas pelos homens que as escreveram"3.

Com essa explicação que evidencia o cerne da preocupação agostiniana, isto é, a compreensão da Revelação divina, o bispo de Hipona aprofunda ainda uma vez seu estudo dos sinais, apresentando uma nova categoria, a dos sinais verbais, para o que recorre primeiro a uma distinção entre sinais visíveis (p. ex., gestos, pantomima teatral) e auditivos, que são muito mais numerosos (plura sunt) e se constituem principalmente de palavras (in verbis maxime).

Antes de prosseguir, é importante ressaltar dois pontos a propósito dessa postulação agostiniana, para contextualizá-la na História de um modo geral e, em particular, na história da filosofia. Para tanto recorremos ao ensaio "Gramática e filosofia - O De Magistro" (Novaes, 2007, p. 47), em que o autor evidencia: 1) que "a tese de que as palavras são signos é resultado de uma peculiar decantação" histórica, bem como que foram os estóicos que inauguraram a "inclusão da linguagem entre os signos". No entanto, isso ocorreu no "quadro de uma teoria da inferência", segundo a qual "na sentença 'se p, então q', o enunciado 'p' é considerado um signo do enunciado 'q", 2) Agostinho deu um passo adiante ao considerar como signo "a palavra tomada isoladamente". Novaes reforça seu parecer citando Eco (1988, p. 42): "no De Magistro, Agostinho operará a fusão definitiva entre teoria dos signos e teoria da linguagem".

Mas, retomando o texto do De doctrina, em II, 3.4, vemos que Agostinho constata o privilégio de que as palavras desfrutam entre os outros sinais, pois "as palavras, com efeito, obtiveram entre os homens o principal lugar para a expressão de qualquer pensamento, sempre que alguém quer manifestá-lo", ou ainda, "a inumerável quantidade de sinais com que os homens demonstram seus pensamentos é constituída pelas palavras". O bispo de Hipona refina ainda mais os seus conceitos em II.4.5, lembrando que "ao vibrar no ar, as palavras logo desaparecem e não duram mais longamente do que ao ressoarem. Para serem fixadas, então, foram instituídos seus signos, por meio das letras (per littera signa verborum). Assim, as palavras manifestam-se aos olhos não por elas próprias, mas pelos sinais que lhes são próprios (Ita voces oculis ostenduntur, non per seipsas, sed per signa quaedam sua.)

A partir daí, Agostinho fará uma breve divagação sobre a diferença das línguas humanas com base no episódio da torre de Babel (Gn, 11, 1-9), para falar das traduções da Bíblia e chegar, afinal, às questões de exegese, pois os que leem a Sagrada Escritura "não desejam encontrar nela mais do que o pensamento e a vontade dos que a escreveram e desse modo chegar a conhecer a vontade de Deus, segundo a qual creem que esses homens a compuseram" (Quam legentes nihil aliud appetunt

\footnotetext{
$2 \mathrm{O}$ galo, quando encontra alimento, com o sinal de sua voz manifesta o achado às galinhas para que acorram a comer", II, 2.3.

${ }^{3}$ Dada a infelicidade da tradução brasileira, com uma repetição do verbo "comunicar" na voz passiva, que não existe em Agostinho, transcrevemos aqui o original: Horum igitur signorum genus, quantum ad homines attinet, considerare atque tractare statuimus, quia et signa divinitus data quae in Scripturis sanctis continentur, per homines nobis indicata sunt qui ea conscripserunt).
} 
quam cogitationes voluntatemque illorum a quibus conscripta est invenire et per illas voluntatem Dei, secundum quam tales homines locutos credimus).

Nesse ponto, podemos deixar de acompanhar o texto de A doutrina cristã, ressaltando o caráter expositivo das menções nele feitas por Agostinho sobre os sinais e as palavras. A obra expõe ao leitor os conceitos em que se basearão suas lições de exegese. Não se detém nas reflexões a que o autor precisou recorrer para chegar a eles e fundamentá-los. No entanto, se queremos avançar na compreensão do pensamento agostiniano, não podemos aceitar esses conceitos como se fossem axiomáticos ou evidentes por si mesmos.

Para nós, leitores do século XXI, impregnados das noções da Linguística e da Semiótica, não é difícil, de fato, compreender rapidamente a ideia de signum, a concepção da palavra como sinal, a noção da distância entre as palavras e as coisas. No entanto, para o próprio autor de A doutrina cristã, a aquisição desses conceitos só podem ter sido resultado de uma aprofundada meditação acerca da linguagem. E, realmente, trata-se de reflexões filosóficas desenvolvidas entre 386 e 391 d.C., muito tempo antes da redação do De doctrina, quando o recém convertido Agostinho, abandonando a carreira de orador e professor de retórica, pôde se dedicar à filosofia, em seu profícuo período de otium liberale iniciado no retiro de Cassissíaco. De seus diálogos desse período, é o De Magistro, provavelmente regidido entre o outono de 388 e o início de 391, que se detém a examinar as palavras e desenvolver uma filosofia da linguagem, embora o escopo da obra seja mais amplo, de caráter epistemológico. Passemos, pois, a seguir as reflexões do filósofo, que irão fundamentar as lições do bispo, vislumbrando a convergência do pensamento agostiniano em duas fases distintas de sua vida.

Para começar, não se pode deixar de dizer que há uma menção ao $D e$ Magistro, nas Confissões (1984), capítulo IX § 6, onde, ao expor as "grandes qualidades" de seu filho, Adeodato, que é personagem do diálogo em questão, ao lado do autor, Agostinho esclarece que "todos os pensamentos aí manifestados por meu interlocutor são realmente dele, então com dezesseis anos". O diálogo também é mencionado nas Retractationum, I, 12.11, onde o autor apenas o apresenta sumariamente, sem lhe fazer qualquer ressalva ou correção: "Na mesma época [quando de seu retorno à África] escrevi o livro intitulado $O$ Mestre, no qual se discute, se investiga e se encontra que o mestre não é aquele que ensina ao homem a ciência, mas Deus, segundo está escrito no Evangelho: "Um só é o vosso mestre, Cristo (Mt 23, 10). Este livro se incia assim: Quid tibi videmur efficere velle, cum loquimur?" (apud Agostinho, 2012, p. 357)

Retenha-se disso que o tema do diálogo não são os sinais nem as palavras, embora eles ocupem treze capítulos dos catorze de que a obra se constitui. Ao longo deles, o autor investiga dialeticamente a linguagem e sua relação com as coisas e o conhecimento das coisas, relação que afinal se revelará enganosa, exigindo que o problema do conhecimento se resolva para além das palavras humanas, com a palavra de Deus, conforme consignada nas Escrituras. Mas não nos adiantemos. Antes, acompanhemos o desenvolvimento de $O$ Mestre, para expor sumariamente alguns de seus aspectos essenciais no que se refere à filosofia da linguagem.

Pois bem, à pergunta "que te parece que queremos levar a efeito quando falamos?", Adeodato não hesita em responder que queremos "ensinar ou aprender" (aut docere, aut discere). O pai concorda, mas apenas com a primeira parte da resposta, estabelecendo, por meio do jogo dialético, que, com a fala, ou ensinamos algo aos outros ou a nós mesmos. Neste último caso, rememoramos, "pois a memória, a que estão inerentes as palavras, revolvendo-as, faz vir ao espírito as próprias coisas, de que as palavras são sinais" (2006, p. 23). É a primeira vez que o conceito de sinal 
(signum) aparece no diálogo. As palavras são sinais porque significam, isto é, "fazem vir ao espírito as próprias coisas", e não podem ser sinais se não significarem, ponto insistentemente enfatizado ao longo de toda a obra. No entanto, Agostinho não se dá por satisfeito com uma conclusão simplista que considera a palavra exclusivamente como uma representação das coisas ${ }^{4}$, caso se entenda "coisas" por entes concretos, como uma pedra ou uma parede (exemplos extraídos do próprio diálogo). Recorrendo ao método dos gramáticos da Antiguidade, o filósofo problematiza esta noção e apresenta ao filho um verso da Eneida - "Si nihil ex tanta Superis placet urbe relingui" - perguntando-lhe o que nele significam as palavras "Si" e "nihil".

Diante disso, Adeodato se esforça para apresentar explicações, que Agostinho encaminha para uma nova conclusão e um novo questionamento: "expuseste palavras por meio de outras palavras, isto é, sinais por sinais, coisas conhecidíssimas por outras igualmente conhecidíssimas. Ora, o que eu queria era que me mostrasses, se fosses capaz, as coisas mesmas de que tais palavras são sinais" (p. 29). Adeodato recorre, então, aos gestos, mas Agostinho rebate, demonstrando que os gestos também são sinais. Depois, detendo-se a considerar a palavra como sinal, conclui que "quando falamos significamos por palavras ou as palavras mesmas ou outros sinais, como quando dizemos gesto ou letra, pois as coisas significadas por estas duas palavras não deixam de ser sinais; ou então uma outra coisa que não seja sinal, como quando dizemos pedra. Efetivamente esta palavra é um sinal, pois significa alguma coisa; mas não se segue que seja um sinal aquilo que por ela é significado" (p. 38).

Note-se que o filósofo estabelece a existência de uma distância entre a palavra e a coisa por ela significada, bem como evidencia que a palavra é palavra em virtude de sua exterioridade, pois se manifesta no mundo do sensível, bem como remete a algo que é exterior a ela mesma, isto é, à coisa. Além disso, insere a palavra, enquanto sinal, no contexto do sensível, captada que ela é pelo ouvido ou pela vista (p. 39). Para tanto, Agostinho examina a relação entre os termos "palavra" e "nome", por meio de um questionamento profundamente sofisticado: "Queria também que me respondesses a um outro ponto. Palavra é sinal de nome; nome é sinal de rio [curso de água], e rio é sinal de uma realidade que já se pode ver. Assim, como disseste, a diferença entre esta palavra e o sinal dela - rio, e entre este sinal e nome, que é sinal deste sinal, qual julgas ser a diferença entre o sinal de nome, que já vimos ser palavra, e o mesmo nome, que é sinal de palavra? (p. 43)

Apesar de ressaltar que, em geral, o significado de nome e de palavra têm a mesma extensão e podem ser intercambiáveis, Agostinho estabelece a diferença entre ambos, considerando para isso uma etimologia das palavras, que, diga-se de passagem, se assemelha àquela desenvolvida por Sócrates no Crátilo: para Agostinho, a palavra (verbum) têm tal significado devido ao fato de "percutir" (verberare) no ouvido; já o nome (nomem) provêm do ato de "conhecer" (noscere), sendo, portanto, a primeira relativa ao sensível e o segundo ao inteligível. Enfim, depois de estabelecer os conceitos que acompanhamos até aqui, Agostinho pede a Adeodato que faça um resumo de tudo o que foi dito, ao fim do qual explica que, com essa conversa toda, não quis empreender um "divertimento trivial" (vilia ludicra), mas visou antes "a exercitar as forças e a vista da mente" (exercendi vires et mentis aciem).

Em Agostinho, "o exercício com o sensível será o prelúdio incontornável para a análise do inteligível", observa com percuciência Novaes (2007, p. 59), e o exercício agostiniano, no diálogo que ora resenhamos, prossegue com o esclarecimento do estatuto de de qualquer diálogo: "de nenhum modo se pode conversar se, ao ouvir as

4 Ao contrário do que afirma Wittgenstein sobre a concepção agostiniana da linguagem, em "Investigações Filosóficas”, cf. Matthews (2007, pp. 43-4). 
palavras, o espírito não é levado às coisas de que elas são sinais" ( $O$ Mestre, 2006, p. 77), isto é, ao ouvirmos a palavra "coisa" não é ao som de suas sílabas que atentamos. Além disso, "a partir da coisa significada é que se aprova ou nega o que se diz" (id., p. 80), com o que Agostinho talvez esteja fazendo uma breve insinuação ao caráter epistemológico com que vai coroar suas cogitações sobre a linguagem. Mas, disso tudo, até esse ponto, o filósofo extrai a seguinte conclusão: "o que é por causa de outra coisa merece necessariamente menos estima do que aquilo por causa do qual é", ou seja, as "realidades significadas devem ser tida em maior conta que os sinais" (id. p. 84).

Considerando, portanto, que os sinais são usados para produzir conhecimento e que o conhecimento é superior aos sinais, Agostinho desenvolve, então, o que é certamente a tese mais radical do diálogo: o sinal não ensina, pois, se conhecemos o sinal, mas não a coisa significada, não sabemos o que o que o sinal significa. Vale a pena transcrever por completo, o trecho em que Agostinho formula essa tese, que lhe permitirá chegar à conclusão do diálogo:

"Com efeito, quando me é dado um sinal, se ele me encontra ignorante da coisa de que é sinal, nada me pode ensinar; se me encontra sabedor, que aprendo eu por meio do sinal? Assim, quando leio 'as suas sarabarae não foram alteradas' (Daniel, 3, 34), essa palavra não me mostra a coisa que significa. Efetivamente, se por este termo se denominam certas coberturas de cabeça, acaso tendo-o eu ouvido aprendi o que é cabeça, ou o que são coberturas? Conhecia já antes essas coisas e o conhecimento delas adveio-me não quando foram denominadas por outras, mas quando vistas por mim. Na verdade, quando essas três sílabas, que pronunciamos ao dizer cabeça, percutiram pela primeira vez em meus ouvidos, desconhecia tanto o que elas significavam, quando ouvi ou li pela primeira vez sarabarae. Mas como se dizia muitas vezes cabeça, eu notando e advertindo quando se dizia, descobri ser o vocábulo de uma coisa que já me era conhecidíssima pela vista. Antes de o ter descoberto, essa palavra era apenas um som para mim; aprendi que era um sinal, quando descobri de que realidade era sinal. Essa realidade, como já disse, tinha-a eu aprendido não por meio de sinal, mas pela visão. E assim, mais se aprende o sinal por meio da realidade conhecida do que a própria realidade por um sinal dado" (id. p. 98).

Agostinho reconhece, assim, a insuficiência das palavras para o conhecimento das coisas. Não deixa, contudo, de reconhecer que elas têm um papel importante nesse processo, na medida em que nos apontam o que devemos conhecer e nos incitam a fazê-lo, conforme diz na conclusão do capítulo X e no início do XI: "Na verdade ao aprender a coisa mesma, não acreditei nas palavras alheias, mas nos meus olhos. Entretanto, talvez acreditasse nelas para atender, isto é, para buscar com a vista o que ia ver. (...) [As palavras] incitam-nos apenas a buscar as coisas, não nô-las apresentam para as conhecermos. Ora quem me ensina alguma alguma coisa é quem me manifesta, quer aos olhos quer a outro sentido do corpo, ou ainda à própria mente, as coisas que eu quero conhecer" (id. p 101).

Desse modo, Agostinho, depois de constatar a insuficiência das palavras e de seu regime de exterioridade, vai buscar o conhecimento na interioridade de sua consciência, interioridade que ocupa, como é notório, um papel decisivo em toda a doutrina agostiniana: "Ora, acerca de todas as coisas que inteleccionamos, não consultamos alguém que fala e produz um som fora de nós, mas a Verdade que preside 
interiormente à nossa mente, sendo talvez incitados pelas palavras a consultá-la. E aquele que é consultado ensina: é Cristo, de quem se disse que habita no 'homem interior' (Efésios, 3, 16-7) e é o 'Poder incomutável de Deus e a sempiterna Sabedoria' (Coríntios, 1, 24). A essa, de fato, toda a alma racional a consulta; ela porém manifesta-se-lhe na medida em que cada um é capaz de a receber, em razão da própria vontade, boa ou má."

Logo a seguir, para melhor esclarecer como se dá essa consulta, Agostinho recorre a uma analogia: "É manifesto que para nos certificarmos acerca das coisas visíveis, recorremos a essa luz [do Sol], para ela nô-las mostrar, na medida em que somos capazes de ver. (...) acerca das cores, certificamo-nos por meio da luz; acerca das outras realidades que sensoriamos por ação do corpo, certificamo-nos por meio dos elementos deste mundo, ou dos mesmos corpos que sensoriamos, e também dos próprios sentidos, de que a mente usa como de intérpretes para conhecer essas realidades. Quanto às realidades que inteleccionamos, certificamo-nos consultando a [luz da] Verdade interior por meio da razão" (id. pp. 104-5).

É preciso esclarecer que essa Verdade interior - e pontanto, imanente - é também, para Agostinho, de maneira decerto paradoxal, uma Verdade transcendente. Nesse ponto, convém lembrar que $O$ Mestre é considerado o mais platônico dos diálogos agostinianos. Ao mesmo tempo, porém, tanto se aproxima quanto se afasta da teoria da reminiscência, que Platão expôs no $\mathrm{Mênon}^{5}$, pois Agostinho não pode aceitar uma existência da alma anterior ao nascimento, o que vai contra os ensinamentos da Igreja. Sobre essa questão, o pensamento de Agostinho já foi muito bem esclarecido por Gilson (2007):

A partir de 387, Agostinho sublinhava o caráter contraditório de uma alma temporal engendrar em si verdades eternas. Logo, o pensamento, que concebe a verdade, obtém de si mesmo o que ele não contém. De onde lhe vem tal riqueza? A verdade permanente do platonismo, aquilo que deve sobreviver ao abandono da reminiscência das ideias como conhecidas no passado, é que o homem não faz a verdade; ele a encontra; não obstante, ele a encontra em condições tais que ela se impõe, da mesma maneira e no mesmo sentido, para além de todas as diferenças de raças, de línguas e de temperamentos, para os indivíduos mais estranhos uns aos outros e mais totalmente diferentes. (p. 151)

Ou, avançando um pouco mais no mesmo sentido:

$\mathrm{Na}$ ordem do sensível, é evidente que, se as cores, os sons, os contatos, são os mesmos em indivíduos diferentes, há sensíveis independentes das sensações que os percebem: há um sol e uma luz comuns a todos os olhares e, se duas vistas podem ver a mesma coisa, é porque a coisa é distinta delas. Do mesmo modo, na ordem do conhecimento inteligível, as verdades, que são percebidas ao mesmo tempo por espíritos diversos, são necessariamente distintas de cada um deles. (...) $O$ mestre verdadeiro é a Verdade, que não é a do professor nem a do aluno, mas comum a ambos, presente em ambos e que, instruindo-os da mesma maneira, os conduz necessariamente a concordarem um com o outro". (p. 152)

\footnotetext{
${ }^{5}$ Segundo os especialistas, Agostinho provavelmente adquiriu conhecimento dessa obra de Platão pela apresentação que dele fez Cícero, nas Tusculanas.
} 
Ápice do diálogo, é esse conhecimento, principalmente, que o pai pretende desvelar ao filho (e ao leitor) em $O$ Mestre, uma vez que a troca de ideias, a conversa, o diálogo entre os homens, em geral, passa a falsa a impressão de que os seres humanos aprendem uns com os outros. Esse mal entendido ocorre, segundo Agostinho, porque "geralmente entre o tempo da locução e do conhecimento não se interpõe nenhum intervalo; e dado que tais homens aprendem interiormente logo depois da insinuação de quem fala, julgam ter aprendido do exterior por meio daquele que o insinuou", pois "o homem, pelas palavras, não é mais que incitado a aprender" e "se realmente se dizem coisas verdadeiras, só o ensina Aquele que, quando nos falavam de fora, nos advertiu que Ele habitava no interior".

Depois de verificar que alguns dos conceitos utilizados em A doutrina cristã provêm das reflexões de $O$ Mestre, que acompanhamos desde o estabelecimento da noção de signum até a superação da linguagem na presença do Verbo divino, não podemos deixar de formular uma conclusão que resulta da leitura de ambas as obras agostinianas. Se a filosofia, por um lado, para Agostinho, aparentemente, precede a doutrina exegética, constituindo um ponto de partida para a correta leitura da palavra sagrada; por outro lado, não se pode deixar de considerar o caminho inverso, em que a interpretação das palavras bíblicas precede a a reflexão filosófica, que se desenvolve a partir dela. Pois, ao encetar o diálogo com Adeodato, Agostinho o conduz, assim como ao leitor, a uma verdade que ele próprio, Agostinho, necessariamente, conheceu antes do filho, verdade que o filósofo deve ter intuído ao defrontar-se pela primeira vez com o versículo de São Mateus $(23,10)$ - "Um só é o vosso mestre, Cristo". É para compreendê-lo, em profundidade muito maior do que a aparente, que Agostinho empreende sua meditação, interpretando-o em chave platônica, o que faz do diálogo como um todo um comentário de caráter exegético às palavras do evangelista.

\section{Bibliografia}

Santo Agostinho, A doutrina cristã, Paulus, São Paulo, 2007.

Idem, O Mestre, Landy Editora, São Paulo, 2006.

Idem, Confissões, Paulus, São Paulo, 2013.

Idem, www.augustinus.it

Auerbach, Erich, Ensaios de Literatura Ocidental, São Paulo, Livraria Duas Cidades/Editora 34, 2007.

Brown, Peter, Santo Agostinho, uma biografia, Rio de Janeiro, Record, 2006.

Gilson, Étienne, Introdução ao estudo de Santo Agostinho, São Paulo, Paulus/Discurso Editorial, 2007.

Marrou, Henri-Irénée, Saint Augustin et la fin de la culture antique, Paris, E. de Boccar, Editeur, 1938.

Matthews, Gareth - Santo Agostinho, a vida e as ideias de um filósofo adiante de seu tempo, Rio de Janeiro, Jorge Zahar Editor, 2007.

Novaes Filho, Moacyr A., A razão em exercício - estudos sobre a filosofia de Agostinho, São Paulo, Discurso Editorial, 2007.

Portalié, E., "Saint Augustin", in Dictionaire de théologie catholique, tomo I, 2, Paris, 1931.

Recebido para publicação em 01-08-15; aceito em 02-10-15 